\title{
The Contributions of Neuromarketing in Marketing Research
}

\author{
Khalid Ait Hammou \\ Alliant School of Management, Alliant International University \\ Tel: 1-619-415-7010Ｅ-mail: Kaithammou@alliant.edu \\ Md Hasan Galib \\ Alliant School of Management, Alliant International University \\ Tel: 1-858-761-1398Ｅ-mail: Hgalib@alliant.edu \\ Jihane Melloul \\ Alliant School of Management, Alliant International University \\ E-mail: jihanemelloul@hotmail.com
}

Received: July 17, $2013 \quad$ Accepted: August 13, $2013 \quad$ Published: October 1, 2013

doi:10.5296/jmr.v5i4.4023 URL: http://dx.doi.org/10.5296/jmr.v5i4.4023

\begin{abstract}
Significant advances in neuroscience in the last couple of decades are finally bringing us closer to a place we have never been before inside the human mind. Research is able to measure brain movement and emotions to see how brain works. Conventional marketing tools have proven to be limited when testing human subjects and have frequently been criticized for their inability to assess consumers' motivations. Although neuromarketing is gaining popularity among professionals and academicians, there are still reservations when it comes to the function of neuromarketing and its level of information accuracy. The emerging field of emotions as a physiological state in marketing has established itself as an important source for marketers and academic research. This article reviews the history of neuromarketing, describes its applications, depicts the challenges in its implementation, and hence explores potential elucidation to ensure effective uses that remain underexplored.
\end{abstract}

Keywords: Neuromarketing, Neuroimaging, Neuroscience, Consumer behavior, FMRI 


\section{Introduction}

Despite centuries of continuous research on human nature, we still seem to understand so little about ourselves. People have always believed that there is more to the human spirit than flesh and blood. Scientists and researchers hold more questions than answers regarding the functioning of the human mind and have struggled to access the processes that occur in the mind in order to decode the outcome of what we see or hear. The science that inspects these facets of the human mind at a biological and theoretical point is neurology. Neurology and marketing have recently come together in a wide range of studies and have provoked an interest, as well as a desire for knowledge, leading to the birth of "neuromarketing" (Marcel et al., 2009).

Recent years have seen considerable progress in neuroimaging, especially functional magnetic resonance imaging (fMRI). Researchers and neuroscientists are starting to comprehensively examine the frequency, location, and timing of neuronal activity to an extraordinary degree to help marketers better understand customers and reduce the millions of dollars spent on conventional marketing tools that show limited results and cannot explain some hidden patterns in human behavior.

Marketing science is still mostly unaware of the colossal potential concerning such advancement and has not yet adopted neuroimaging as a standard technique for prospective marketing research as a way to predict consumer behavior (Braeutigam, 2005; Kenning \& Plassmann, 2005; Rustichini, 2005). Marketing scientists have been too slow to weigh the tremendous advantages of imaging methodologies despite its significant benefits in reflective decision making. The exploitation of neuroimaging in market research, or what has come to be called neuromarketing, has recently elicited significant controversy among neuroscience circles, especially when it comes to ethical issues and privacy (Lee et al., 2006). The purpose of fMRI and other neuroimaging technologies for neuroimaging is mainly to explore the underpinnings of emotions and social interactions that drive people to make specific choices (Fisher et al., 2010).

During the last decade, innovation in neuroimaging techniques have shown considerable advances and was successful to spread its usability in different branches. But social sciences and especially marketing are still lagging behind because of many reasons that this article will try to answer. The present review strives to give an academic perspective on the emerging field of neuromarketing and provide a detailed description of the technologies used in this promising science, especially fMRI, which is currently the most employed functional brain imaging technique in marketing. Subsequently, we intend to discuss not only the challenges and limitations of these technologies but also the ways in which these new experimental techniques will allow us to gain a better understanding of consumer behavior. These challenges and limitations are aimed to highlight the restrictions that neuroimaging technologies face in order to gain success in marketing research. Our main purpose is to draw attention to neuromarketing, as well as to increase our knowledge in its fundamental implications with marketing and management. 


\section{Investigating the Scope of Neuromarketing}

Diverse fields have recently adopted the prefix neuro- including neuroaesthetics, neurotheology, and neuroeducation, which has elicited a kind of "neuroculture." The surfacing of a neuroculture helps translate brain-based narratives regarding personal identity, responsibility, and causation into palpable information (Frazzetto \& Anker, 2009). Neuromarketing, an emerging branch of marketing, has derived its components from the collaboration of neuroscience research and business. Neuroscience appeared when Italian scientist Angelo Mosso (1881) discovered that the pulsation changes during mental or emotional activity also affect blood flow and its redistribution across the human body. Mosso's experiment concluded that when the subject began experiencing emotional or mental activity, the sphygmograph recorded an increase in the subject's pulsations and blood flow in his system (James, 1890).

BrightHouse, an Atlanta marketing firm, first used the term neuromarketing in an article published in June 2002. The firm, which sponsored the interference of neurophysiologic research into marketing fields, established a business division that uses fMRI for marketing research purposes and now has more than 500 consumer-product companies as clients (Fisher et al., 2009; Thompson, 2003).

Neuromarketing uses neuroscience technologies like fMRI scanners to ensure a better understanding of the human brain's subconscious reaction toward advertising, brands, and products. This burgeoning aptitude helps researchers look closely inside the black box of the brain to distinguish how it handles images and messages and how people make specific decisions. The cutting-edge technology gives marketers a potentially clear idea so that they can craft their marketing strategies appropriately for better products, services, ads, and marketing campaigns. Neuromarketing is used to carry out neurological studies intended for marketing purposes that mainly include analyzing customer behavior. The technologies used are mainly medical diagnostic devices that play the role of mind readers for marketers: fMRI, electroencephalography (EEG), magnetoencephalography (MEG), and transcranial magnetic stimulation (TMS). These medical devices are utilized to obtain brain image responses toward experimental stimuli such as commercials, printed ads, movie trailers, speeches, and even games. For data analysis, researchers may use different software packages to help analyze a consumer's data images, but the most widely used software for analysis of brain imaging data sequences is statistical parametric mapping. The purpose behind analyzing data images is basically to identify how well and how often the brain appointed the areas for attention, emotion, memory, and personal implication. The analyzed data can explicitly inform marketers about a consumer's thoughts while watching the experimental content. Correspondingly, marketers can recognize whether the participant was scared, sleepy, happy, or interested by examining how the product or the commercials are affecting the consumer's brain.

Neuromarketing is widely defined as the science that uses MRI, EEG, TMS, MEG, fMRI, and other brain wave tools to view the human brain's responses to marketing stimuli to figure out what customers' thoughts are toward a product, service, advertisement, or even packaging 
to perfectly construct marketing campaigns that are based on the human brain's response. The definition of neuromarketing has been strongly debated in the past years by researchers who classify it as a pure scientific field rather than a business one (Lee et al., 2006) and those who perceive it as a pure business activity rather than an academic field. They proposed naming neuromarketing as "consumer neuroscience" (Fisher et al., 2010; Hubert \& Kenning, 2008). Similar definitions educe abundant explanations and are common in the neuroscience literature. But it is clear that the academic foundation for neuromarketing is not yet established, and the literature is still questioning whether it qualifies as an academic field like neuroeconomics, which went through major theoretical changes in the past years (Fisher et al., 2010). Fugate (2007) emphasized in his conclusion that for neuromarketing to be a legitimized academic field, it is necessary to create a behavioral model that can predict what type of consumption-related problems or stimuli (marketing stimuli) the studied brain structures need to solve. According to Fugate, creating this model will not happen in the near future, as it requires a shift in focus from neural science to experimental research in neuromarketing and the adoption of new roles that will advance the field. Such justifications require researchers, marketers, and firms that are using neuromarketing methodologies to share and publish their data and results. This will help establish reliable validation that neuromarketing is not incompatible with consumer interests and can also demonstrate that consumers might have more understanding of themselves as it relates to decision making, which can give more information to policy makers and lead to more intelligent policies and legislation (Fugate, 2007).

\section{Neuromarketing and Consumer Behavior}

Marketing research is about discerning, explaining, and anticipating consumer behavior relevant to individuals, groups, and organizations. Marketing research comprises a wide range of disciplines beyond consumers' persuasion toward buying a certain product. The "buy button" is a significant area of interest in the eyes of academic researchers just like the "love button" to psychological scholars (Lee et al., 2006). Neuroscience has demonstrated that a consumer buys a certain product not just because of its characteristics, cost, or the product's advertising message but mainly on the basis of an intuitional relation with the product's brand. Consumer perceptions about brands are built gradually through time and experiences that help extract evaluations in the customer's mind. This explains why, for example, certain consumers go to McDonald's or wear fashionable sneakers; it is not because of the way the product looks, tastes, or fits but rather because of the way the product or the service perfectly matches their lifestyle. Consumers buy products according to the way their brains envision the products and the extent to which they identify themselves with the goods they buy and how those goods could harmonize perfectly with their lives. Neuromarketing intervenes to help marketers understand the way a consumer's brain perceives different brands and identify multiple factors determining the choice. Christophe Morin, a marketing specialist and coauthor of Neuromarketing: Understanding the "Buy Button" in Your Customer's Brain, determined some key points of neuromarketing as a way for companies to enhance their products, services, and marketing strategies. Morin (2007) stated that consumers' choices are made subconsciously, in the posterior regions of the mind, "the 
primal brain areas" where basic "fight-or-flight" instincts or basic strong buy buttons exist. According to Morin, consumers are absolutely self-centered, which means that people buy goods that will make a difference to their lives, abolish pain, or bring them more enjoyment. Neuromarketing studies have shown that consumers crave contrast, since consumers are captivated by the ad that comprises considerable contrast over 10,000 typical ads. Similarly, consumers prefer concrete visuals instead of abstract written ad messages, since visual memory can generate a greater impact and lead to more rationalized choices. According to Morin's study, people like to experience emotions because emotion creates a chemical change in the brain similar to the way hormones flood the brain and alter the pace with which neurons interconnect; hence, people remember those connections. fMRI experiments have recognized that brain parts such as the orbitofrontal cortex and ventromedial prefrontal cortex are active in brand selection and constantly determine various procedures of individual subjective value, including willingness to pay (Chib et al., 2009; Montague et al., 2006; Plassmann et al., 2007; Venkatraman et al., 2012) and relative value (FitzGerald et al., 2009).

A multitude of companies worldwide have hired neuromarketing agencies to conduct intelligent studies for the purpose of discovering consumers' underpinnings of buying decisions. A significant neuromarketing study conducted by Daimler Chrysler in 2002 granted a better understanding of people's reactions to cars (Hunt, 2008). The subjects were shown different images of car grilles. It was later discovered that a division in the respondents' brains called the fusiform face area, or the portion of the temporal lobe that enables facial recognition, was highly active. Researchers subsequently hypothesized that the main motive behind the outstanding sales of BMW's Mini Cooper was, at least subconsciously, its adorable design. The study's findings have also demonstrated that pictures of high-performance cars such as the Ferrari 360 Modena and the BMW Z8 have excited some brain areas related to the concepts of wealth and social power. Such findings have provided the company with pure and absolute emotional responses that no focus group or survey could ever reveal (Hunt, 2008). According to Lindstrom (2008), neuromarketing studies display unexpected results confirming that people do not always know what lies beneath their unconscious minds. For example, a study conducted by Lindstrom (2008) detected that warning pictures on cigarette packages do not prevent people from buying cigarettes, yet it provokes some parts of the brain to light up a cigarette. But when respondents were asked to recall the negative consequences of cigarette consumption in the long term in a study conducted by the Department of Psychiatry at Yale University, subjects reduced their craving for smoking. Brain scans showed an increased motion in the region responsible for goals setting, planning, and controlling behavior (the dorsolateral prefrontal cortex), which in turn inhibited the ventral striatum, the part of the reward pathway that generates craving (Kober et al., 2010).

Similarly, Lindstrom's conclusions proved that people do not always say what they want nor explicitly what they really mean, since some fMRI scanning pictures revealed that people do like television shows although they confirmed a priori that they do not like them at all. The American company - No Lie MRI reported that the current accuracy of fMRI and other similar scanning techniques are over $90 \%$ and can even attain $99 \%$ accuracy once product 
development is complete (Blakemore, 2010). Similarly, another fMRI experiment examining consumers' behavioral response to wines revealed an intensification of consumers' neural activity and pleasantness when tasting the most expensive wine even though in reality all tested wines were the same (Garcia \& Saad, 2008). Hence, the study affirmed that price recognition has a direct impact on consumers' behavioral response, since the higher the price, the more positive the behavioral response toward wine quality.

The Hollywood film industry has also benefited from the use of neuromarketing through the emergence of neurocinema. Ale Smidts (2002), a Dutch marketing expert, coined the term neurocinema and predicted its future intensity and popularity. Several years later, Lacey (2010) defined neurocinema as an offshoot of neuromarketing. A year before Avatar hit screens worldwide, James Cameron asserted that fMRI machines demonstrated that more neurons were active while watching his film in 3-D than while watching it in a conventional form (Desaulniers, 2013; Randal, 2011). This offshoot of neuromarketing got intensive mass media attention, and the San Diego-based firm MindSign Neuromarketing was the first neuromarketing firm to create a revolution in this industry through the use of fMRI to test and track the impact of scenes and analyze significant activity on the prospect's brain. MindSign's efforts in this segment of neuromarketing were rapidly spread out by mass media including CNN, National Public Radio, Science Channel, and Wired magazine when they offered free services including fMRI brain scans of subjects exposed to Avatar trailers. Neurocinema is truly one of the fascinating branches of neuromarketing that has proved profitable for business, manifestly for Avatar.

Studies on neuromarketing have elicited valuable outcomes. Danish marketer Martin Lindstrom has brought neuromarketing to life through his writing Buyology: Truth and Lies About Why We Buy. Lindstrom and Oxford University researchers scanned the brains of more than 2,000 subjects around the world as they watched several advertising and marketing materials such as logos, product placements, health warnings, and subliminal images. Lindtsrom's study concluded that branding can emphasize and optimize all brand's signals and more precisely the direct ones (Shaw et al., 2008). Further, Lindstrom has also discovered that what people hear and smell is more powerful than what they see, which was considered an outrageous result of the study, since it is paradoxical to previous evidence claiming that the vision sense is the most influential. Lindstrom revealed that emotional engagement is a prominent influential factor, since people's buying decisions are based on emotional factors rather than rational ones. Subsequently, marketing campaigns have to focus more sharply on displaying influential emotional features and not just relying on standard visuals (O’Dwyer, 2009). Similarly, Gemma Calvert, cofounder of the marketing consulting agency Neurosense, claimed that the firm discovered that consumers considered watching a $\mathrm{TV}$ ad more enjoyable than listening to a radio ad; nevertheless, the radio ad was more memorable (Jones, 2006). Calvert's conclusion goes hand in hand with Lindstrom's in stating that emotional aspects of the ad are more leading than the visual ones. To understand the reasons behind consumers' buying decisions, a study cited in Plassmann, Ambler, Braeutigm and Kenning (2007) demonstrated that very unattractive ads were nearly as often recalled as very attractive ads. The study implied that the use of faces that have positive impressions are 
perceived as attractive, whereas advertisements using text-based information and faces that have neutral expressions are perceived as purely unattractive (Kenning et al., 2007). Noticeably, neuromarketing has illuminated the cognitive process behind buying decisions to help understand what motivates people to buy both tangible and intangible goods (Fugate, 2008). Further research in neuromarketing has gone beyond exploring end consumers' decision making to tackle more complex areas such as trust, pricing, and negotiation (Lee et al., 2006). Neuroscientific studies have provided significant insight into the nature and development of trust (Morgan \& Hunt, 1994). Neuroimaging techniques have detected that the caudate nucleus, which is often in action while learning about stimuli-response relations, is highly concerned in experimental games calling for some kind of trust (King-Casas et al., 2005). Understanding and investigating the nature of trust will lead to greater ability to examine the antecedent factors to trust, and hence help firms build trust with customers and collaborators for mutually beneficial outcomes. Despite the huge amount of behavioral research that often relies on consumers' assumptions to explore pricing, neuroimaging studies are likely to offer considerable insight into the nature of price information. Neuroscientific studies have evidenced that the price of a basic product such as sugar differs in nature from the price of a conspicuous product such as a Nike sports shoe or even a Porsche sports car, which has been proven through changes in the location of activity in the brain once the prices are perceived along with their associations (Lee et al., 2006). Such research offers substantial insight into situations where outwardly rational information is processed in decision making. Neuroimaging has already begun to explore negotiating behavior; a study by Sanfey et al. (2003) has demonstrated that emotion along with rational cognition highly influences negotiation, particularly when offers are regarded as unfair. Such fMRI studies will help ascertain when and how consumers let their emotions dominate their rationality when negotiating prices or deals. Therefore, exploring the neuronal activity underlying suboptimal behaviors related to trust, price, and negotiation will give clear insight into consumers' decision making and will increase mutually beneficial outcomes (Lee et al., 2006).

\section{Neuromarketing's Limitations}

The implementation of neuromarketing techniques holds a promising future for marketing research; nevertheless, this new practice is facing numerous limitations, including cost, complexity, and sometimes the size of the equipment, such as the fMRI scanners (Bogue, 2010). According to Kenning et al. (2007), a typical fMRI scanner can cost between 1 to 2 million Euros (\$1.3 to $\$ 2.6$ millions) depending on the resolution and some other variables, such as the cost of the software, hardware maintenance, professional charges, as well as the costly process utilized to cool down the magnetic coils in the machine, which can increase the total cost per study much higher than any other conventional market research methodologies. Damon Collins, executive creative director of Rainey Kelly Campbell Roalfe/Y\&R, stated, "Conventional research is expensive enough. Having to stick every respondent into an MRI scanner at $£ 1,000$ a pop might be pushing clients’ budgets a little” (Lovell, 2008).

Complexity of fMRI machines represents an arduous challenge for marketers and researchers because it recommends sophisticated experimental designs compared to simple designs presented in conventional market research. fMRI relies also on a wide range of stimulus 
presentation repetitions as a way to reduce the noise in the fMRI signal through averaging across a large number of trials that will definitely limit the effectiveness of complicated studies (Kenning et al., 2007). Complex studies have to come up with special methods to ensure the accuracy of results. For example, a Coke and Pepsi fMRI study used cooled plastic tubes held with plastic mouthpieces to enable participants to fully taste a sufficient volume of both sodas while lying inside the scanner. A computer-controlled syringe pump allowed precise and accurate delivery of both sodas (McClure et al., 2004).

The medical environment, the gigantic size of the machine, and the highly clustered space may also impede the perceived fruitfulness of real-world marketing stimuli. For example, an fMRI study examining the perceived trustworthiness of eBay offers is difficult to conduct within a real environment. Such a study recommends that the online shoppers sit in front of their computers in a comfortable and calm environment to examine eBay offers, which is impossible to implement in real experimental life because of the size of the van as well as the subsistence of a special room to control the safety of both subjects and researchers (Riedl et al., 2010). Some researchers perceive that neuromarketing studies will be translated to pure scientific projects rather than marketing ones, arguing that the implementation of such techniques will convert the art of selling to an absolute scientific task (Lovell, 2008).

Like traditional market research, there must be accurate requirements for different control conditions. Yet the complexity of neurophysiological processes dictates a comprehensive understanding of the specific neuroscientific techniques in order to properly test a suggested hypothesis and evaluate the study's findings (Kenning et al., 2007). Hence, researchers may have difficulty testing all subjects to ensure that they are free from any medical or behavioral disorder and controlling the movements of the subject's body, mainly the head, which might affect the scanning pictures (Maxwell, 2008). The subject has to remain immobile while being surrounded by an acoustically noisy scanner for at least 45 minutes to an hour and a half, depending on the study in question, which may discomfit the subject (Riedl et al., 2010). According to Kenning et al. (2007), to process and interpret neuroimaging data is much more complex than doing the same for general behavioral data or information-based data derived from questionnaires, since the brain itself is extremely complex. Kenning et al. also affirmed not only that the nature of the neuroimaging technique is complicated but also that the affiliation between performance and the underlying humankind physiology is considered a new issue for market researchers.

Neuromarketing has elicited controversial ethical concerns, since some critics argued that neuromarketing will not only take pure information from customers but also use it to extract their freedom (Appleyard, 2008). Lovell (2008) argued that neuromarketing will enable big firms to monitor customers' freedom and treat them as laboratory rats if used offensively and impertinently. The integration of neuroscience in marketing alerted various critics who feared that the discovery of the buy button could turn individuals into buying robots. Numerous researchers claimed that advertisements and marketing activities may be displayed in order to produce dangerous impacts, such as overconsumption. Once the buy button is determined, unethical companies will unscrupulously take advantage of the existing information to create addiction for their products and brands to the detriment of consumers' physical and mental 
health, according to Gary Ruskin, executive director at Commercial Alert (Marcel et al., 2004).

Despite the existence of a consent form representing an agreement of understanding the aim of the study and the use of the images in research purposes, there are still some critics who demand the implementation of appropriate laws and regulations to prevent probable privacy issues (Rapp et al., 2009). Another alarming dimension resides in the implicit manipulation and exploitation of customers by marketers who may use neurological triggers to further embed their brands (Fleming, 2006). Kenning et al. (2007) pointed out that the public might disregard the neurobiological and mechanical restrictions of neuroimaging techniques and consequently treat initial results as an indisputable truth that will limit further critical discussions.

\section{Neuromarketing Challenges}

fMRI technology has enabled researchers and marketers to go above and beyond conservative marketing research through truly understanding customers' thinking to engender informed marketing and sales approaches. To carry on the emergent technology to the next generation, research has to be conducted assertively and fruitfully to enrich the academic relevance and managerial implementation. Butler (2008) affirmed that the threat menacing this stage resides in the fact that all the focus would be centered on addressing the specific needs of academic peer reviews without taking into consideration the wider social environment. fMRI technology limitations need to be challenged, particularly the cost of research initiation, which has to be lower than the conventional research as a way to encourage further affluent fMRI studies. While neuromarketing is unlikely to be cheaper than conventional marketing tools in the near future, there is rising evidence that it might supply hidden information concerning the consumer's past experience (Ariely \& Berns, 2010).

Koller (2008) suggested an intensified methodological mix of qualitative and quantitative approaches in marketing research, as consumer behavior is getting more complex and variable over time. This methodological mix will undeniably serve some multi-complex brain-related fields such as consumer behavior, since the researchers can examine the issue from various angles. Intensifying fMRI studies will definitely build up empirical evidence and mature the technology that is constantly developing.

To solve the ethical issues bounding the integration of fMRI technologies in marketing, Naish (2009) proposed that the technology has to be developed further from the pessimistic "brainwashing machine" that meticulously examines people's intentions and feelings. Naish suggested that researchers and marketers need to seize the mainstream issues and then apply the appropriate methods to study those issues, such as green marketing and name it "neurogreen." Professor Tracey, director of the Oxford University Centre for fMRI in the United Kingdom, assumed that researchers and scientists will eventually be able to electronically capture the essence of whatever makes a person if fMRI techniques have been improved and overcome all of its limitations (Rudall \& Mann, 2009). 
We can infer from these challenges and limitations that the use of neumarketing techniques in near future is far from the reach of many marketers and practitioners. Methodological complexities and finances are the main causes that restrict the development of neuroimaging techniques in the marketing field. Such complexities will vanish by time as new advanced techniques will presume to this promising science which will lead marketers to alter their perception about the usability of those techniques in marketing. Making the neuroimaging techniques user friendly can also be a decisive factor in the expansion of its usability among marketing professionals.

\section{Conclusions}

In today's visual pollution, considering customers' behavior and understanding the underlying causes behind their purchasing decisions are key success factors for any company. To obtain immediate and accurate feedback on any product or brand, companies have to reduce their dependence on traditional focus groups and other conventional marketing strategies. The information collected from focus groups might not be reliable; the signals generated from the brain are more apt to deliver truthful feelings and thoughts. What neuroscience has really shown us is that everything we do is filtered by our emotions first. What you see and what you pay attention to are filtered by your emotional state. The future of neuromarketing is promising and presents the standpoint of a quantitative method to inspect the success of promotional contents before expending big budgets on promotional media. It has been increasingly gaining ground in recent years, as it offers a better understanding of the targeted audience's decision-making process to craft better products and services appropriately. This decision-making process is a far more complex process, and there is no single buying button. Every decision involves different areas of the brain that are being pulled in different directions by varying factors.

In general, concerns about privacy and ethics in neuromarketing research are misplaced and overblown, as there is no mind reading that goes beyond the conventional sense and could read somebody's thoughts precisely, and it is not possible to happen in the near future. We had superb advertising for many decades, and using neuroscientific techniques can advance the quality of ads, but it is very unlikely that even with some better market research data from brain scans, marketers can create ads that can turn us into a subject like Pavlov's dog. Each culture is unique, and therefore the impact of ads on our emotional engagement toward commercials would be limited.

\section{References}

Ariely, D., \& Berns, G. (2010). Neuromarketing: The hope and hype of neuroimaging in business. Nature Reviews Neuroscience, 11, 284-292. http://dx.doi.org/10.1038/nrn2795

Blakemore, C. (2010, February 5). Do we want brain scanners to read our minds? The Daily Telegraph. Retrieved from http://www.telegraph.co.uk/science/7159464/Do-we-want-brain-scanners-to-read-our-minds. html. 
Bogue, R. (2010). Brain-computer interfaces: Control by thought. Industrial Robot: An International Journal, 37(2), 126-132. http://dx.doi.org/10.1108/01439911011018894

Braeutigam, S. (2005). Neuroeconomics - from neural systems to economic behaviour. Brain Research Bulletin, 67, 355-360. http://dx.doi.org/10.1016/j.brainresbull.2005.06.009

Butler, M. J. R. (2008). Neuromarketing and the perception of knowledge. Journal of Consumer Behaviour, 7, 415-419. http://dx.doi.org/10.1002/cb.260

Chib, V. S., Rangel, A., Shimojo, S., \& O’Doherty, J. P. (2009). Evidence for a common representation of decision values for dissimilar goods in human ventromedial prefrontal cortex. Journal of Neuroscience, 29(39), 12315-12320. http://dx.doi.org/10.1523/JNEUROSCI.2575-09.2009

Desaulniers, M. (2013, March 25). Does the science of neuromarketing rest on solid ground or is it just hype? Retrieved from http://suite101.com/article/the-science-of-neuromarketing-a221593

Fisher, C. E., Chin, L., \& Klitzman, R. (2010). Defining neuromarketing: Practices and professional challenges. Harvard Review of Psychiatry, 18(4), 230-237. http://dx.doi.org/10.3109/10673229.2010.496623

FitzGerald, T. H. B., Seymour, B., \& Dolan, R. J. (2009). The role of human orbitofrontal cortex in value comparison for incommensurable objects. Journal of Neuroscience, 29, 8388-8395. http://dx.doi.org/10.1523/JNEUROSCI.0717-09.2009

Fleming, J., (2006). Is That a Neuromarketer in Your Brain? The Gallup Management Journal, 1-4, Retrieved May 2, 2013, from http://gmj.gallup.com/content/20785/neuromarketer-your-brain.aspx

Frazzetto, G., \& Anker, S. (2009). Neuroculture. Nature Reviews Neuroscience, 10(11), 815-821. http://dx.doi.org/10.1038/nrn2736

Fugate, D. L. (2007). Neuromarketing: A layman's look at neuroscience and its potential application to marketing practice. Journal of Consumer Marketing, 24(7), 385-394. http://dx.doi.org/10.1108/07363760710834807

Fugate, D. L. (2008). Marketing services more effectively with neuromarketing research: A look into the future. Journal of Services Marketing, 22(2), 170-173. http://dx.doi.org/10.1108/08876040810862903

Garcia, J., \& Saad, G. (2008). Evolutionary neuromarketing: Darwinizing the neuroimaging paradigm for consumer behavior. Journal of Consumer Behaviour, 7, 397-414. http://dx.doi.org/10.1002/cb.259

Hubert, M. and Kenning, P. (2008), A current overview of consumer neuroscience. Journal of Consumer Behaviour, 7, 272-292. http://dx.doi.org/10.1002/cb.251

Hunt, K. (2008, October 31). Brand surgery. The Globe and Mail. Retrieved from http://www.theglobeandmail.com/report-on-business/brand-surgery/article718559/ 
James, W. (1890). The principles of psychology (Vols. 1-2). New York, NY: Henry Holt.

Jones, M.C. (2006). What were you thinking? Brand Strategy, 2, 56-57. Retrieved May 12, 2013, from http://www.highbeam.com/doc/1G1-141736140.html

Kenning, P., \& Plassmann, H. (2005). Neuroeconomics: An overview from an economic perspective. Brain Research Bulletin, 67, 343-354. http://dx.doi.org/10.1016/j.brainresbull.2005.07.006

Kenning, P., Plassmann, H., \& Ahlert, D. (2007). Applications of functional magnetic resonance imaging for market research. Qualitative Market Research: An International Journal, 10(2), 135-152. http://dx.doi.org/10.1108/13522750710740817

King-Casas, B., Tomlin, D., Anen, C., Camerer, C., Quartz, S., \& Montague, P. R. (2005). Getting to know you: Reputation and trust in a two-person economic exchange. Science, 308(5718), 78-83. http://dx.doi.org/10.1126/science.1108062

Kober, H., Kross, E. F., Mischel, W., Hart, C. L., \& Ochsner, K. N. (2010). Regulation of craving by cognitive strategies in cigarette smokers. Drug and Alcohol Dependence, 106, 52-55. http://dx.doi.org/10.1016/j.drugalcdep.2009.07.017

Koller, M. (2008), A future research agenda for mixed-methods designs in business research. International Journal of Business Research, 8(4), 50-60.

Lacey, L. (2010, April, 3). This is your brain at the movies. The Globe and Mail (Canada).

Lee, N., Broderick, L., \& Chamberlain, L. (2006). What is "neuromarketing"? A discussion and agenda for future research. International Journal of Psychophysiology, 63, 200-204.

Lindstrom, M. (2008, November 16). Buy.ology: How Everything We Believe About Why We Buy Is Wrong. The Sunday Times. Retrieved from http://www.thesundaytimes.co.uk/sto/culture/books/non_fiction/article131594.ece

Lovell, C. (2008, October 3). Close-up: Live issue - Is neuroscience making a difference? Campaign. Retrieved from http://www.campaignlive.co.uk/news/851185/Close-Up-Live-issue---neuroscience-making-di fference/?DCMP=ILC-SEARCH

Marcel, C., Lăcrămioara, R., Ioana, M. A., and Maria, Z. M. (2009). Neuromarketing- getting inside the customer's mind. Annuals of faculty of economics, 4(1), 804-807

Maxwell, S. (2008). Fair price: Research outside marketing. Journal of Product and Brand Management, 17(7), 497-503. http://dx.doi.org/10.1108/10610420810916399

McClure, S. M., Li, J., Tomlin, D., Cypert, K. S., Montague, L. M., \& Montague, P. R. (2004). Neural correlates of behavioral preference for culturally familiar drinks. Neuron, 44, 379-387. http://dx.doi.org/10.1016/j.neuron.2004.09.019 
Montague, P. R., King-Casas, B., \& Cohen, J. D. (2006). Imaging valuation models in human choice. Annual Review of Neuroscience, 29, 417-448. http://dx.doi.org/10.1146/annurev.neuro.29.051605.112903

Morgan, R.M. and Hunt, S.D. (1994). The commitment-trust theory of relationship marketing. Journal of Marketing, 58, 20-38. http://dx.doi.org/10.2307/1252308

Mosso, A. (1881). Ueber den kreislauf des blutes im menschlichen gehirn [On the circulation of the blood in the human brain]. Leipzig, Germany: von Veit.

Naish, J. (2009, February 28). Can a machine read your mind? The Times. Retrieved from http://www.thetimes.co.uk/tto/health/article1964392.ece

O’Dwyer, E. (2009, March 26). Marketers tap into our biology to boost sales. The Sydney Morning Herald. Retrieved from http://www.smh.com.au/lifestyle/life/marketers-tap-into-our-biology-to-boost-sales-2009040 7-9wzg.html

Plassmann, H., Ambler, T., Braeutigam, S., \& Kenning, P. (2007). What can advertisers learn from neuroscience? International Journal of Advertising, 26(2), 151-175.

Plassmann, H., O’Doherty, J., \& Rangel, A. (2007). Orbitofrontal cortex encodes willingness to pay in everyday economic transactions. Journal of Neuroscience, 27(37), 9984-9988. http://dx.doi.org/10.1523/JNEUROSCI.2131-07.2007

Randal, K. (2011, February 25). Rise of neurocinema: How Hollywood studios harness your brainwaves to win Oscars. Fastcompany. Retrieved from http://www.fastcompany.com/1731055/rise-neurocinema-how-hollywood-studios-harness-yo ur-brainwaves-win-oscars

Rapp, J., Hill, R. P., Gaines, J., \& Wilson, R. M. (2009). Advertising and consumer privacy: Old practices and new challenges. Journal of Advertising, 38(4), 51-61. http://dx.doi.org/10.2753/JOA0091-3367380404

Renvoisé, P., \& Morin, C. (2007). Neuromarketing: Understanding the "Buy Button" in Your Customer's Brain. Thomas Nelson Inc,

Riedl, R., Hubert, M., \& Kenning, P. (2010). Are there neural gender differences in online trust? An fMRI study on the perceived trustworthiness of eBay offers. MIS Quarterly, 34(2), $397-428$.

Rudall, B. H., \& Mann, C. J. H. (2009). Next-generation technology: Challenges and applications. Kybernetes, 38(9), 1426-1432. http://dx.doi.org/10.1108/03684920910991432

Rustichini, A. (2005). Neuroeconomics: Present and future. Games and Economic Behavior, 52, 201-212. http://dx.doi.org/10.1016/j.geb.2005.05.004

Sanfey, A. G., Rilling, J. K., Aronson, J. A., Nystrom, L. E., \& Cohen, J. D. (2003). The neural basis of economic decision-making in the ultimatum game. Science, 300, 1755-1758. http://dx.doi.org/10.1126/science.1082976 
Shaw, R. L., Senior, C., Peel, E. A., Cooke, R., \& Donnelly, L. S. (2008). Ethical issues in neuroimaging health research: An IPA study with research participants. Journal of Health Psychology. http://dx.doi.org/10.1177/1359105308097970

Smidts, A. (2002). Kijken in het brein: Over de mogelijkheden van neuromarketing [Look in the brain: On the possibilities of neuromarketing]. Inaugural Addresses, Research in Management Series, Erasmus Research Institute of Management.

Thompson, C. (2003, October 26). There's a sucker born in every medial prefrontal cortex. New York Times Magazine. from http://www.nytimes.com/2003/10/26/magazine/26BRAINS.html?ex=1068147831\&ei=1\&en

Venkatraman, V., Clithero, J. A., Fitzsimons, G. J., \& Huettel, S. A. (2012). New scanner data for brand marketers: How neuroscience can help better understand differences in brand preferences. Journal of Consumer Psychology, 22(1), 143-153. http://dx.doi.org/10.1016/j.jcps.2011.11.008 